\title{
A Micro-Scaled Graphene Based Tree-Shaped Wideband Printed MIMO Antenna For Terahertz Applications
}

K. Vasu Babu ( $\sim$ vasubabuece@gmail.com )

Vasireddy Venkatadri Institute of Technology https://orcid.org/0000-0003-2602-2825

\section{Sudipta Das}

IMPS College of Engineering and Technology

Gaurav Varshney

NIT Patna: National Institute of Technology Patna

Gorre Naga Jyothi Sree

Vignan's Foundation for Science Technology and Research

Boddapati Taraka Phani Madhav

Koneru Lakshmaiah Education Foundation

\section{Research Article}

Keywords: THz communication, MIMO Antenna, Wideband, diversity gain, chemical potential, isolation

Posted Date: August 31st, 2021

DOl: https://doi.org/10.21203/rs.3.rs-839983/v1

License: (c) (i) This work is licensed under a Creative Commons Attribution 4.0 International License. Read Full License 


\title{
A Micro-Scaled Graphene based Tree-Shaped Wideband Printed MIMO Antenna for Terahertz Applications
}

\author{
K. Vasu Babu ${ }^{1 *}$, Sudipta Das², Gaurav Varshney ${ }^{3}$, Gorre Naga Jyothi Sree ${ }^{4}$, Boddapati Taraka \\ Phani Madhav ${ }^{5}$
}

\begin{abstract}
${ }^{1}$ Department of Electronics \& Communication Engineering, Vasireddy Venkatadri Institute of Technology, Nambur, Guntur, A.P, India.

${ }^{2}$ Department of Electronics and Communication Engineering, IMPS College of Engineering and Technology, Malda, West Bengal, India. Email:sudipta.das1985@gmail.com

${ }^{3}$ Department of Electronics and Communication Engineering, National Institute of Technology, Patna, Bihar, India

${ }^{4}$ Department of Electronics and Communication Engineering, VFSTR (Deemed to be University), AP, India ${ }^{5}$ Department of Electronics and Communication Engineering, Koneru Lakshmaiah Education Foundation, Guntur, AP, India.
\end{abstract}

"Corresponding author’s mail id : vasubabuece@gmail.com 


\begin{abstract}
A tree-shaped graphene based microstrip MIMO antenna for terahertz applications is proposed. The proposed MIMO antenna is designed on a $600 \times 300 \mu \mathrm{m}^{2}$ polyimide substrate. The designed MIMO antenna exhibits a wide impedance bandwidth of $88.14 \%(0.276-0.711 \mathrm{THz})$ due to the suggested modifications in the antenna configuration. The MIMO design parameters like total active reflection coefficient (TARC), mean effective gain (MEG), envelope correlation coefficient (ECC) and diversity gain (DG), Channel capacity loss (CCL) are evaluated and their values are found within acceptable limits. The proposed MIMO structure offers $M E G \leq-3.0 \mathrm{~dB}, \mathrm{TARC} \leq-$ $10.0 \mathrm{~dB}, \mathrm{DG} \approx 10 \mathrm{~dB}, \mathrm{CCL}<0.5 \mathrm{bps} / \mathrm{Hz} / \mathrm{sec}$ and $\mathrm{ECC}<0.01$ at the resonant frequency. At the resonant frequency, the isolation between the radiating elements of the proposed MIMO is recorded as $-52 \mathrm{~dB}$. The variations in operating frequency and S-parameters are also analyzed as a function of the chemical potential $\left(\mu_{\mathrm{c}}\right)$ of the graphene material.The parametric analysis, structural design evolution steps, surface current distribution, antenna characteristics parameters and diversity parameters are discussed in detail in this paper. The designed MIMO antenna is suitable for high speed short distance communication, video rate imaging, biomedical imaging, sensing, and security scanning in the THz frequency band.
\end{abstract}

Keywords: THz communication, MIMO Antenna, Wideband, diversity gain, chemical potential, isolation

\title{
1. Introduction
}

Over the last few decades, the modern trend of wireless communication shows increasing demand for faster data rates and as a result, an astounding evolution has been witnessed in the field of wireless communication technology [1]. The remarkable research developments in mobile communication systems ( $3 \mathrm{G}$ to $5 \mathrm{G}$ ) have opened up many new application opportunities by ensuring enhanced data connectivity [2-3]. So, it is becoming essential to have a massive operating frequency spectrum to meet the requirements of next-generation communication applications. But in the coming future, $5 \mathrm{G}$ technology in the mm-wave band will not be sufficient to satisfy the global need of gigantic data rate in terabits/sec (Tbs) and enormous channel capacity for rapidly growing applications like Tbps Internet of things (Tera-IoT), ultra-wideband $\mathrm{THz}$ space communication and secure high speed short-range indoor communication [4-5]. The possible key 
wireless technology can be terahertz wireless communications (TeraCom)with its potential operating bands from 0.3 to $10 \mathrm{THz}$ (as per IEEE standard) to fulfill the future demands of wireless systems [6].In present years, the researchers are carrying out tremendous research activities on shorter wavelength terahertz communication to unlock and utilize its wider segments of available bandwidth for future large-scale applications in civilian and commercial domains. However, apart from promising opportunities, critical issues like very high propagation path loss and limited communication distance are also associated with $\mathrm{THz}$ communications. It is worthy to note that the characteristics of the $\mathrm{THz}$ antenna directly influence the performance of the $\mathrm{THz}$ systems. So, the compact efficient $\mathrm{THz}$ antennas are in high demand for the radiation and detection of $\mathrm{THz}$ waves. Significant contributions have been reported by investigating the advantageous properties of conducting materials like gold [7] and graphene [8-11] for designing highly efficient $\mathrm{THz}$ antennas.

The requirements of high performance characteristic parameters for micro/nano-scaled $\mathrm{THz}$ antenna have created many new challenges as well as possibilities that will definitely help in the advancement of antenna technology. The widely reported $\mathrm{THz}$ antenna designs include the metallic antenna [12], dielectric antenna [13], photoconductive antenna [14], on-chip antenna [15], metamaterial loaded antenna [16], substrate integrated waveguide (SIW) based antenna [17], leaky wave antenna [18], lens antenna [19] and horn antenna [20], however, the complex design process, higher manufacturing cost, larger dimensions and difficulty in integration with planar circuits are the major concerns of these $\mathrm{THz}$ antenna structures. On the other hand, with the growing popularity of planar technology, microstrip antenna has become the point of attraction for terahertz short range wireless applications due to its various advantages like low cost, design simplicity, light weight and compact size. Despite significant advantages, it suffers from narrow bandwidth which limits its applications in the wide $\mathrm{THz}$ regime. So, the challenge is to design compact, less voluminous antennas with wide operating bandwidth to support multiple applications in the $\mathrm{THz}$ frequency band. In the literature, researchers have designed and reported some compact $\mathrm{THz}$ antennas but they are capable to operate with very narrow bandwidths of 5.85\% [21], 8.2\% [22], $3.78 \%$ [23], and $6.67 \%$ [24], which restricts their suitability for a wideband short distance high speed wireless $\mathrm{THz}$ communications. So, the researchers have proposed different design methods to improve the bandwidth of the microstrip antenna in the $\mathrm{THz}$ regime by implementing photonic crystal structures [25-26], photonic crystal based frequency selective surface [27], electromagnetic 
crystal substrate [28], unslotted simple rectangular patch [29-30], adding superstrate [31] and incorporating slots on patch [32]. Also, a multi-layer array antenna is investigated and proposed in ref. [33]. However, these reported $\mathrm{THz}$ antenna structures show improvement in operating bandwidth at cost of a larger antenna dimension. The authors of these reported papers designed only single antenna element for single input single output wireless communication systems and also these reported wideband single element $\mathrm{THz}$ antennas face the challenge of fading for high speed short-range wireless applications at THz frequency band. This issue of signal fading can be easily overcome by utilizing the spatial diversity multiple-input and multiple-output (MIMO) technique. In this context, very recently in the year 2021, Okan et al. [34] has published his findings on $\mathrm{THz} 2 \times 2 \mathrm{MIMO}$ antenna which exhibits an impedance bandwidth of $0.114 \mathrm{THz}$ (from 0.093 to $0.207 \mathrm{THz}, 76 \%$ fractional bandwidth) and isolation less than-17 $\mathrm{dB}$ but at the cost of large antenna dimension of $2000 \times 1000 \times 100 \mu \mathrm{m}^{3}$. In ref. [35], Singh et al. reported another MIMO antenna of $1600 \times 800 \mathrm{~mm}^{2}$ dimension that operates from 0.618 to $1 \mathrm{THz}$ with $57.96 \%$ fractional bandwidth.

This motivated the authors of this paper to design and analyze a compact microstrip MIMO antenna with wide impedance bandwidth and better diversity performance for high speed short range wireless communication systems in the $\mathrm{THz}$ band. In this paper, the authors have designed a two-element spatial diversity multiple-input multiple-output (MIMO)THz antenna which occupies less area and offers much better impedance bandwidth compared to the reported single element antennas [25-32], array antenna [33] and MIMO antennas [34-35]. The reason behind the selection of spatial diversity MIMO antenna is to exploit its multipath characteristics to provide high data rate, better channel capacity, interference mitigation, extended coverage, and improved signal reliability by avoiding fading.

In this proposed work, a tree-shaped MIMO antenna is designed using a polyimide substrate. Graphene is employed as the conducting material to design the patch and gold is used at the ground plane of the suggested antenna configuration. Due to the suggested patch and monopole ground plane structure in the design, the operating bandwidth of the proposed MIMO structure is improved. The proposed MIMO structure with an attractive size of $600 \mu \mathrm{m} \times 300 \mu \mathrm{m}$ maintains the impedance bandwidth from $0.276 \mathrm{THz}$ to $0.711 \mathrm{THz}$ with $\mathrm{S}_{11} \leq-10 \mathrm{~dB}$. The maximum peak efficiency and gain of the proposed MIMO design are $84 \%$ and $3.9 \mathrm{dBi}$. The suggested MIMO 
antenna is useful for high speed short range communication in indoor environments, video rate imaging, biomedical imaging, sensing, and security scanning in the terahertz frequency band.

The main highlights and novelties of the proposed design are as follows

i. The proposed graphene based planar MIMO antenna is designed with microstrip technology. Hence, it is less voluminous, light-weight, easy to design and requires less implementation cost compared to other types of available $\mathrm{THz}$ antennas [12-20].

ii. The proposed antenna exhibits a much wider $-10 \mathrm{~dB}$ impedance bandwidth $(0.276$ $0.711 \mathrm{THz}$ ) of $88.14 \%$ compared to other reported THz microstrip antennas [21-35]

iii. The proposed printed MIMO antenna is designed with two radiating patch elements but still, it occupies less implementation area of $600 \times 300 \mu \mathrm{m}^{2}$ compared to the previously reported single element antennas [25-35].

iv. The proposed MIMO structure offers better diversity performance parameters (MEG $\leq$ $-3.0 \mathrm{~dB}, \mathrm{TARC} \leq-10.0 \mathrm{~dB}, \mathrm{DG} \approx 10 \mathrm{~dB}, \mathrm{CCL}<0.5 \mathrm{bps} / \mathrm{Hz} / \mathrm{sec}$ and $\mathrm{ECC}<0.01)$ which helps to overcome the challenges associated with short-distance communication like signal fading, multipath propagation and increased interference. Hence it is preferable as compared to the reported single input single output (SISO) microstrip THz antenna structures [21-32] and array structure [33] to support high speed short distance communication at terahertz frequency with more data rate and reliability.

v. The proposed MIMO antenna provides a much better impedance bandwidth of 0.435 $\mathrm{THz}(0.276-0.711 \mathrm{THz}$, fractional $\mathrm{BW}=88.14 \%)$ and isolation characteristics (less than $-20 \mathrm{~dB}$ across the entire working band) in a more compact dimension of $600 \times 300 \times 45 \mu \mathrm{m}^{3}$ as compared to the recently reported THz MIMO antennas [34-35].

vi. The MIMO antenna is having isolation of less than-20 dB across the whole wideband of operation; therefore it can be applied for point to point communication at $\mathrm{THz}$ frequency. 


\section{Proposed wideband THz MIMO Antenna Design and Investigation on characteristics of graphene material in $\mathrm{THz}$ band}

\subsection{Structure of the proposed MIMO Antenna}

The structure of the proposed tree-shaped MIMO antenna for THz applications is shown in Fig. 1. The front face of the structure is displayed in Fig. 1(a) which shows the tree shaped patch elements connected with the microstrip feed line. Fig. 1(b) represents the rear face of the structure which indicates the partial rectangular ground planes of the proposed MIMO antenna. The suggested structure is designed by cutting the edges of a circular shaped patch suitably to form a tree-shaped metallic patch structure. On the bottom plane, individual rectangular monopole ground planes are designed for the patches to achieve wide-band resonance characteristics in the operating terahertz band. The proposed MIMO design has been executed on a polyimide substrate with a dielectric constant of 4.3 , loss tangent 0.004 , and thickness of $45 \mu \mathrm{m}$. The graphene material with a thickness of $0.0355 \mu \mathrm{m}$ is considered for designing the patches on the top layer while gold as a conducting material is employed for the design consideration of the ground plane of this suggested THz MIMO antenna design. The overall area of the proposed MIMO structure is $\mathrm{W} \times \mathrm{L}=600 \times 300 \mu \mathrm{m}^{2}$. A microstrip feeding line of $60 \mu \mathrm{m}$ is used to utilize the feed power for the current MIMO structure through a 50 ohms SMA connector for producing effective radiations which ensure that the maximum amount of power is transferred at the input. The major structural parameters of the proposed MIMO antenna as represented in Fig. 1 are summarized in Table 1.

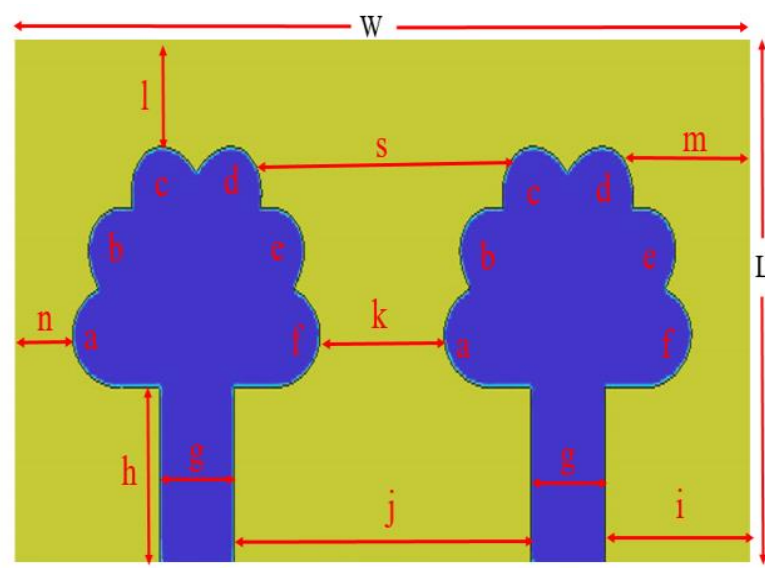

(a) Front view

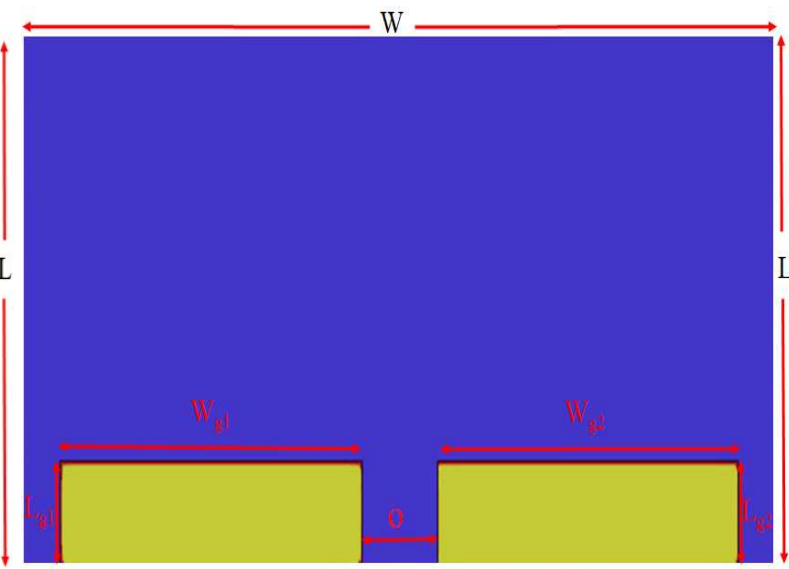

(b) Back view

Fig. 1 Proposed THz MIMO antenna 
Table 1: Design parameters (Units in $\mu \mathrm{m}$ )

\begin{tabular}{|c|c|c|c|c|c|c|c|c|c|c|c|}
\hline Parameter & $\mathrm{W}$ & $\mathrm{L}$ & $\mathrm{a}$ & $\mathrm{b}$ & $\mathrm{c}$ & $\mathrm{d}$ & $\mathrm{e}$ & $\mathrm{f}$ & $\mathrm{g}$ & $\mathrm{h}$ & $\mathrm{s}$ \\
\hline Unit & 600 & 300 & 59.5 & 52.9 & 56.1 & 56.1 & 52.9 & 22 & 59.5 & 100 & 195 \\
\hline Parameter & $\mathrm{i}$ & $\mathrm{j}$ & $\mathrm{k}$ & $\mathrm{l}$ & $\mathrm{m}$ & $\mathrm{n}$ & $\mathrm{o}$ & $\mathrm{W}_{\mathrm{g} 1}$ & $\mathrm{~L}_{\mathrm{g} 1}$ & $\mathrm{~W}_{\mathrm{g} 2}$ & $\mathrm{~L}_{\mathrm{g} 2}$ \\
\hline Unit & 120 & 240 & 180 & 110 & 100 & 90 & 60 & 240 & 60 & 240 & 60 \\
\hline
\end{tabular}

\subsection{Design evolution of the proposed antenna}

The step-by-step design analysis of the THz MIMO design is demonstrated in Figs.2 (a)-(c). The corresponding S-parameters of each designed stage are presented in Figs. 3(a)-(b). In stage 1 of the design evolution process, the radiating patches are considered as simple rectangular shapes with partial rectangular ground planes as indicated in Fig. 2(a). In this stage, the antenna resonates at $0.628 \mathrm{THz}$ with $\mathrm{S}_{11}$ of $-20.75 \mathrm{~dB}$ and $\mathrm{S}_{21}$ of $-10 \mathrm{~dB}$. In stage 1 of the design, the antenna shows an impedance bandwidth of $266 \mathrm{GHz}(0.486 \mathrm{THz}-0.752 \mathrm{THz})$. Fig. 2(b) shows the second step of the design process. In stage 2 of the design evolution process, the structure of the radiating patches has been modified to form a new front plane geometry by adding three ellipses within the rectangular patches to improve the reflection and transmission coefficient parameters. The ground plane remains the same as observed in stage 1. In stage 2, the designed antenna resonates at 0.698 THz with $\mathrm{S}_{11}$ of $-32.43 \mathrm{~dB}$ and $\mathrm{S}_{21}$ of $-24.23 \mathrm{~dB}$. So, significant improvement is noticed in terms of return loss and isolation compared to stage 1 . But the operating bandwidth of the antenna is not enhanced as per expectations with the suggested change in antenna geometry as presented in Stage 2 of the design process. In stage 2, the overall bandwidth is enhanced by $25 \mathrm{GHz}$ and the new operating bandwidth is $291 \mathrm{GHz}$ ranging from $0.461 \mathrm{THz}-0.752 \mathrm{THz}$. Finally, to bring further improvement in operating bandwidth, reflection coefficient and isolation, the structure of the antenna has been further modified in stage 3 (proposed MIMO antenna) of the design process as indicated in Fig. 2(c). In the front plane of the geometry, another three ellipses are introduced within the patches which resemble a tree-shaped and in the backplane, individual monopole ground planes are used to provide major improvements in bandwidth, reflection coefficient, and isolation values. At this final stage, the resonant frequency is shifted to a lower size and the proposed antenna resonates at $0.472 \mathrm{THz}$ with $\mathrm{S}_{11}$ of $-38.43 \mathrm{~dB}$ and $\mathrm{S}_{21}$ of $-52.86 \mathrm{~dB}$. Due to the suggested changes in the final antenna geometry, the operating bandwidth is enhanced by an amount of 144 $\mathrm{GHz}$ as compared with the previous design step (stage-2). The proposed MIMO antenna provides wide operating bandwidth of $0.435 \mathrm{THz}(0.276-0.711 \mathrm{THz}$, fractional $\mathrm{BW}=88.14 \%)$. 


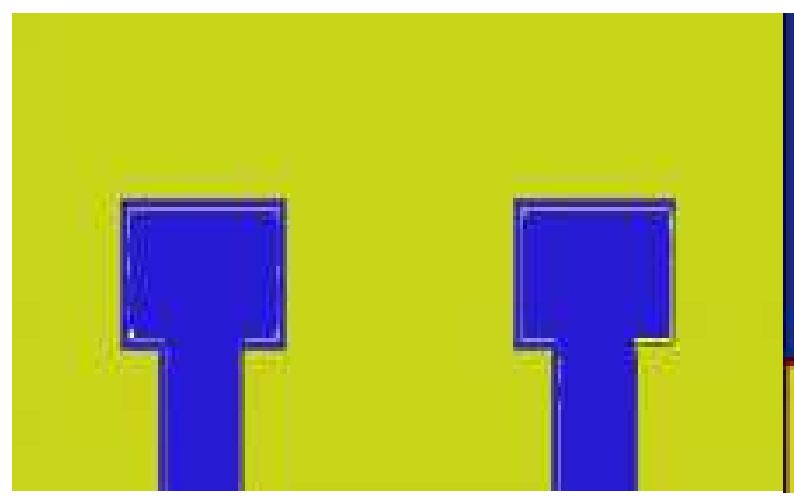

Design stage 1 front view (patch)

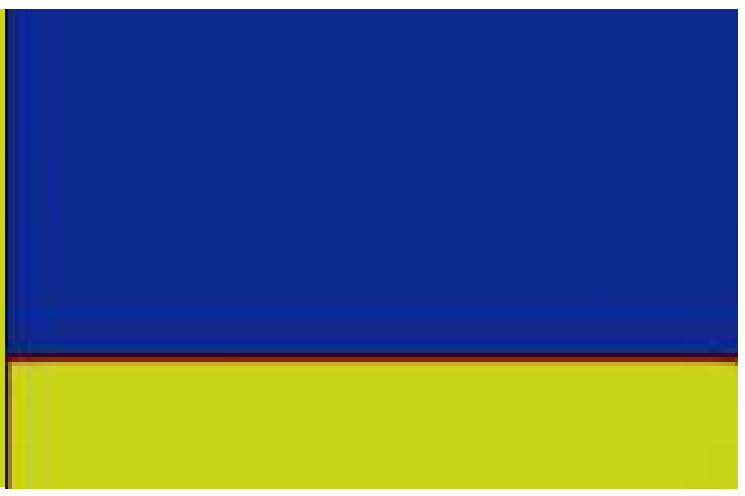

Design stage 1back view (ground plane)

(a)

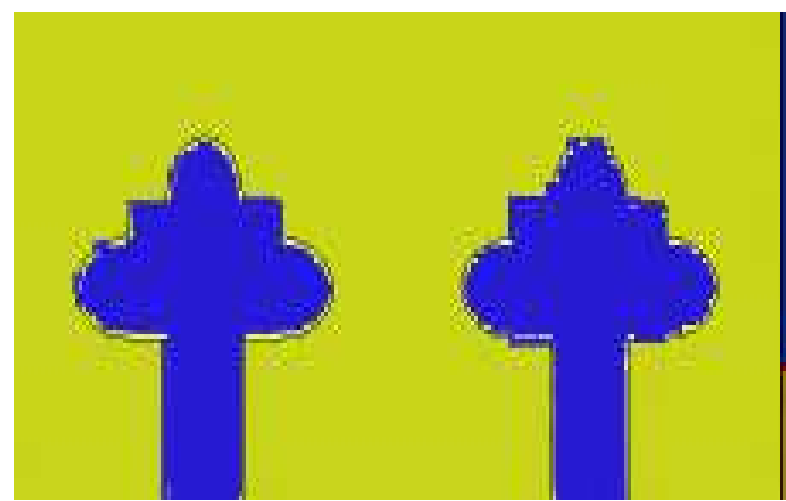

Design stage 2 front view (patch)

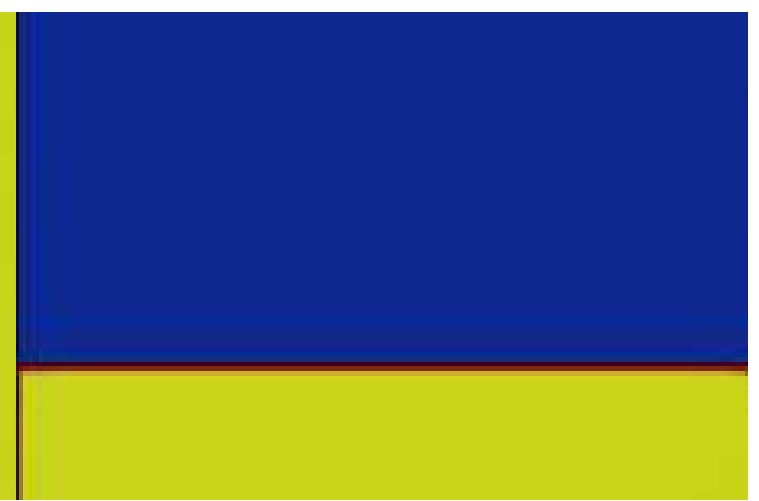

Design stage 2 back view (ground plane)

(b)

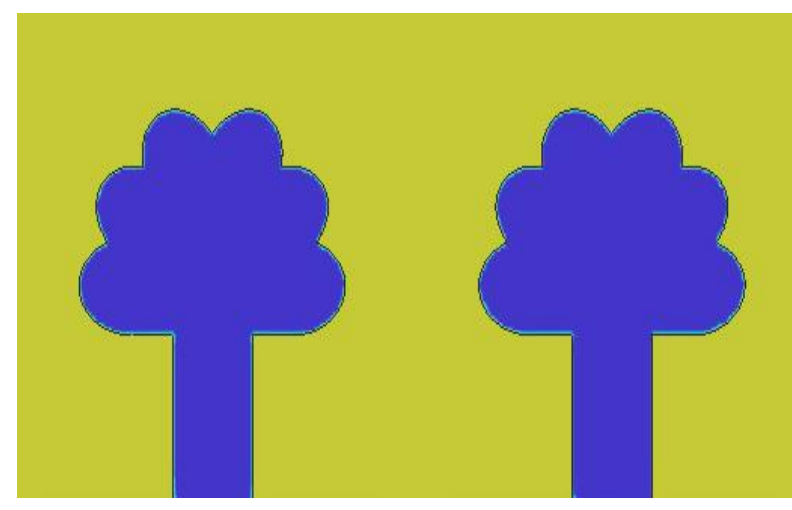

Design stage 3 front view (patch)

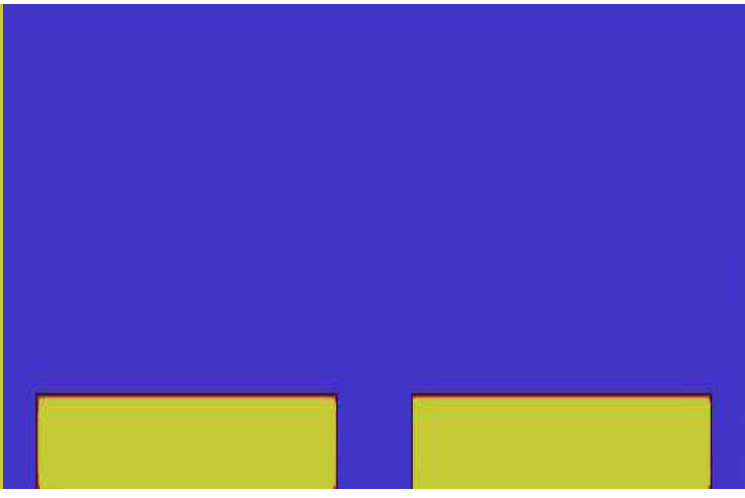

Design stage 3 back view (ground plane)

(c)

Fig. 2. Design evolution stages of the proposed THz MIMO antenna 


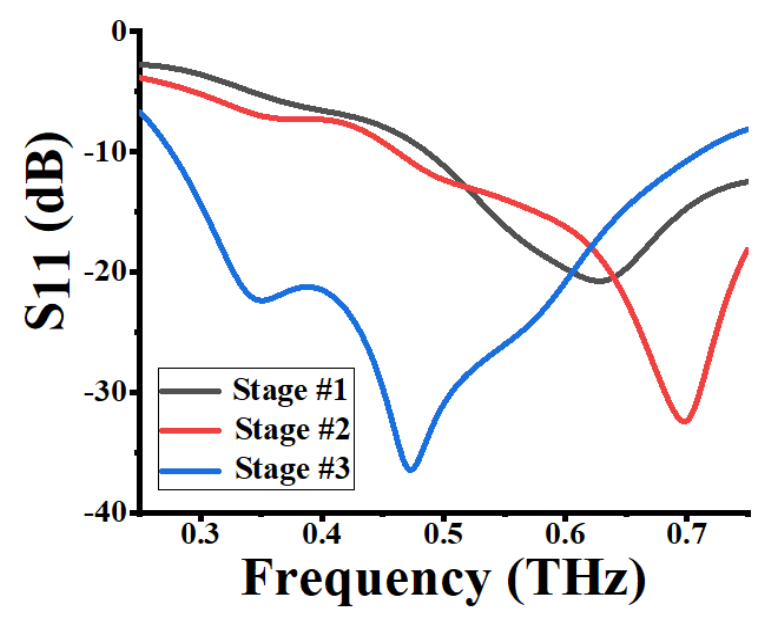

(a)

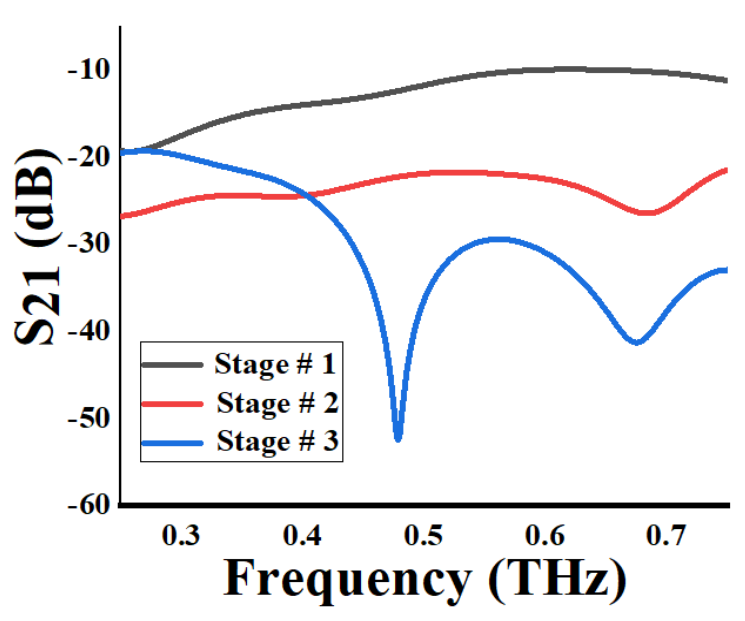

(b)

Fig. 3. S-parameters at different design development stages (a) $S_{11}$ and (b) $S_{21}$

\subsection{Characteristic analysis of graphene}

The graphene material shows higher thermal and electrical conductivity compared to copper and silver. The graphene material offers high charge carrier mobilities which allow the electrons to move with minimal resistance in graphene material and this enables a much faster speed of electricity than conventional metal. This property helps in the formation of unique electromagnetic radiation in the $\mathrm{THz}$ frequency of operation compared to conventional metal based antennas. The surface conductivity parameter of graphene material varies with temperature $(\mathrm{T})$, radian frequency $(\omega)$ chemical potential $\left(\mu_{\mathrm{c}}\right)$, bias magnetostatic field $\left(\mathrm{B}_{0}\right)$ and scattering rate $(\Gamma=1 / \tau)$. The applied electrostatic field is expressed in terms of chemical potential. For the field $\mathrm{B}_{0}=0$, the graphene Hall's conductivity becomes zero. According to the kubo's reports, ' $\sigma_{\mathrm{g}}$ ' is a combination of diagonal and Hall's conductivity. Thus, the component of ' $\sigma_{\mathrm{g}}$ ' is occurred only due to the field component $\left(\mathrm{E}_{0}\right)$ which is called the diagonal conductivity. For graphene material, the diagonal conductivity is the combination of Intraband and interband transitions [36]. The real part of the interband conductivity at lower frequencies remains negligible as reported in [37]. In this case of our designed MIMO structure, ' $\sigma_{\mathrm{g}}$ ' is obtained only by the intraband contribution as it works at terahertz frequency.According to Drude's form representation, the intraband conductivity for graphene reported [38] can be represented as in equation (1)

$$
\sigma_{\text {intraband }}\left(\omega, \mu_{c}, \Gamma, T\right)=-j \frac{e^{2} K_{B} T}{\pi h^{2}(\omega-j 2 \Gamma)} \times\left(\frac{\mu_{c}}{K_{B} T}+2 \ln \left(e^{\frac{-\mu_{c}}{K_{B} T}}+1\right)\right)
$$


Where, $\mathrm{h}$ is Planck's constant, $\mathrm{k}_{\mathrm{B}}$ represents Boltzmann's constant ande is the charge of an electron.

$$
\sigma_{\text {interband }}\left(\omega, \mu_{\mathrm{c}}, \Gamma, \mathrm{T}\right) \approx \frac{-\mathrm{je} \mathrm{e}^{2}}{4 \pi \mathrm{h}} \ln \left(\frac{2\left|\mu_{\mathrm{c}}\right|-(\omega-\mathrm{j} \Gamma) \mathrm{h}}{2\left|\mu_{\mathrm{c}}\right|+(\omega-\mathrm{j} \Gamma) \mathrm{h}}\right)
$$

The approximated interband conductivity of graphene is expressed in equation (2). It is approximated by the condition $\mathrm{K}_{\mathrm{B}} \mathrm{T} \approx\left|\mu_{\mathrm{c}}\right|$ and $\mathrm{K}_{\mathrm{B}} \mathrm{T} \approx \mathrm{h} \omega$. From equation (2), it can be observed that $\sigma_{\text {interband }}$ is imaginary with a corresponding negative magnitude at the lower frequency range. At higher frequency, it becomes complex with real part value $\pi \mathrm{e}^{2} / 2 \mathrm{~h}$ and the corresponding imaginary part value is negative. Here $\mathrm{K}_{\mathrm{B}} \mathrm{T} \approx\left|\mu_{\mathrm{c}}\right| ; \quad \mathrm{K}_{\mathrm{B}} \mathrm{T} \approx \mathrm{h} \omega ; \mathrm{h} \omega=2\left|\mu_{\mathrm{c}}\right|$

The characterization of graphene material is done by its displacement vector $\left(D_{n}\right)$ which is normal to the surface of the graphene patch. For homogenous dielectric material, the displacement vector of the graphene patch is $D_{n}=e_{s} / 2=\varepsilon_{s} E_{0}$. Where $\varepsilon_{s}$ is the permittivity of the homogenous dielectric, $\mathrm{n}_{\mathrm{s}}$ is the two-sided graphene surface charge density [39]. The surface charge density can be evaluated by using equation (3).

$$
\mathrm{n}_{\mathrm{s}}=\frac{2}{\pi \mathrm{h}^{2} \mathrm{v}_{\mathrm{f}}^{2}} \int_{0}^{\infty} \mathrm{E}\left(\mathrm{f}_{\mathrm{d}}(\mathrm{E})-\mathrm{f}_{\mathrm{d}}\left(\mathrm{E}+2 \mu_{\mathrm{c}}\right)\right) \mathrm{dE}
$$

Here, $f_{d}(E)$ represents the Fermi-Dirac distribution function which is in terms of energy, $f_{d}(E)=\left(e^{\frac{E-\mu_{c}}{k_{B}^{T}}+1}\right)^{-1}$

The electric field expression according to the application was modified as given by equation (4) reported in [36].

$$
\frac{2 \varepsilon_{s} E_{0}}{e}=\frac{2}{\pi h^{2} v_{f}^{2}} \int_{0}^{\infty} E\left(f_{d}(E)-f_{d}\left(E+2 \mu_{c}\right)\right) d E
$$

The chemical potential variation with respect to the externally applied DC bias voltage can be easily evaluated using equation (5) reported in [40].

$$
\mathrm{V}=\mathrm{V}_{0}+\frac{t e \mu_{c}^{2}}{\varepsilon_{o} \varepsilon_{\mathrm{r}} \pi \mathrm{h}^{2} \mathrm{v}_{\mathrm{f}}^{2}}
$$


From the expression of the non-linear equation, it can be concluded that the conductivity of graphene completely depends on its chemical potential $\left(\mu_{c}\right)$. The value of $\mathrm{V}_{0}$ provides that voltagedependent parameter compensation to the chemical potential $\left(\mu_{\mathrm{c}}\right)$. In this DC bias voltage expression ' $\mathrm{t}$ ' indicates thickness and $\varepsilon_{\mathrm{r}}$ indicate permittivity of a dielectric substrate. Here $\mathrm{V}_{0}$ is considered as zero. Fig. 4 represents the real and imaginary parts of the intraband conductivity of the graphene at $0.16 \mathrm{eV}$.

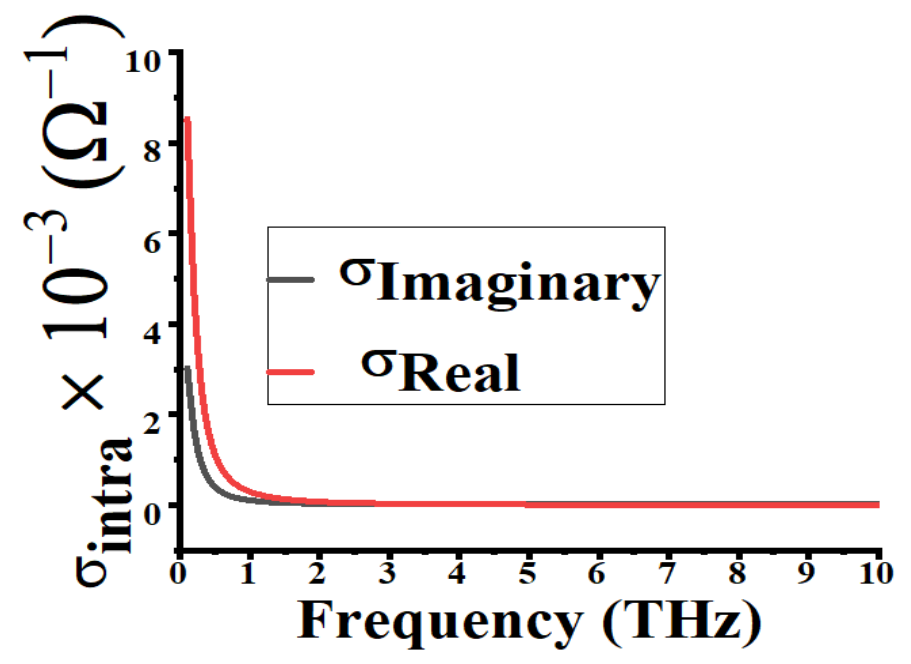

Fig. 4. Graphene Intraband conductivity $\left(T=300 \mathrm{k}, \mu_{\mathrm{c}}=0.18\right.$ and $\left.\tau=1 \mathrm{ps}\right)$

\section{Parametric variations of the MIMO Design}

\subsection{Effect of structural parameters on $S_{11}$ and $S_{21}$ characteristics}

The parametric investigation has been carried out to observe the effect of various major structural parameters on the reflection coefficient and isolation characteristics of the suggested MIMO design. The dimension of feed line width ' $\mathrm{g}$ ' and inter-element spacing of two patches ' $\mathrm{k}$ ' play a vital role in achieving the desired resonance responses. All the parametric studies have been performed and analyzed by varying only one structural parameter at a time while keeping all other parameters fixed to their optimized dimensions. The variations in $S_{11}$ and $S_{21}$ parameters as a function of geometrical parameter ' $\mathrm{g}$ ' are shown in Figures 5(a)-(b). The variations in the response of reflection coefficient $\left(\mathrm{S}_{11}\right)$ and isolation $\left(\mathrm{S}_{21}\right)$ are observed by setting the dimension of the parameter $\mathrm{g}=50 \mu \mathrm{m}, 55 \mu \mathrm{m}$ and $60 \mu \mathrm{m}$. It is clearly presented in Fig. 5(a) that best impedance matching is obtained for the proposed value of $\mathrm{g}=60 \mu \mathrm{m}$ and thus the reflection coefficient reaches a maximum level of $-39 \mathrm{~dB}$ at $0.472 \mathrm{THz}$ for the proposed dimension of $\mathrm{g}$. Also, maximum -10 
$\mathrm{dB}$ bandwidth is attained when the parameter $\mathrm{g}$ is set to an optimized value of $60 \mu \mathrm{m}$. Similarly, the variations in transmission coefficient $\left(\mathrm{S}_{21}\right)$ vs. frequency due to change in parameter ' $\mathrm{g}$ ' is plotted in Fig. 5(b). The isolation of the designed MIMO structure reaches its best value of -52 $\mathrm{dB}$ at $0.472 \mathrm{THz}$ and also the isolation below $-20 \mathrm{~dB}$ is maintained across the whole operating band for the proposed value of $\mathrm{g}=60 \mu \mathrm{m}$. When the parameter ' $\mathrm{g}$ ' is changed from the optimized value to 50 and $55 \mu \mathrm{m}$, the isolation value decreases to -19 , and $-21 \mathrm{~dB}$ at the resonant frequency of $0.472 \mathrm{THz}$ and also the overall isolation value is degraded across the entire operating band. The influence of design parameter ' $k$ ' on $\mathrm{S}_{11}$ and $\mathrm{S}_{21}$ characteristics is demonstrated in Figs. 5(c)-(d). Significant variations are observed in terms of reflection coefficient and isolation characteristics due to a change in parameter $k$ that specifies the spacing between the patch elements. The changes in reflection coefficient and isolation are recorded by varying the distance between the patches ' $\mathrm{k}$ ' with $180 \mu \mathrm{m}, 170 \mu \mathrm{m}$ and $160 \mu \mathrm{m}$. It can be noticed that the values of $S_{11}$ and $S_{12}$ parameters get improved with an increase in parameter $\mathrm{k}$. As indicated in Fig. 5(c), the maximum reflection coefficient of $-39 \mathrm{~dB}$ at the resonant frequency of $0.472 \mathrm{THz}$ is obtained for the proposed value of $\mathrm{k}=180 \mu \mathrm{m}$. Any further changes in parameter $\mathrm{k}(170 \mu \mathrm{m}$ and $160 \mu \mathrm{m})$ lead to degradation in the $S_{11}$ parameter and also shift in resonant frequency. Similarly, Fig. 5(d) represents as per expectation that the maximum isolation $\left(\mathrm{S}_{21}\right)$ at the resonant frequency along with best isolation characteristics across the entire operating band are obtained for the suggested value of $\mathrm{k}=180 \mu \mathrm{m}$. So, the selection of optimized values of these design parameters ( $\mathrm{g}$ and $\mathrm{k}$ ) are justified according to their $S_{11}$ and $S_{21}$ responses.

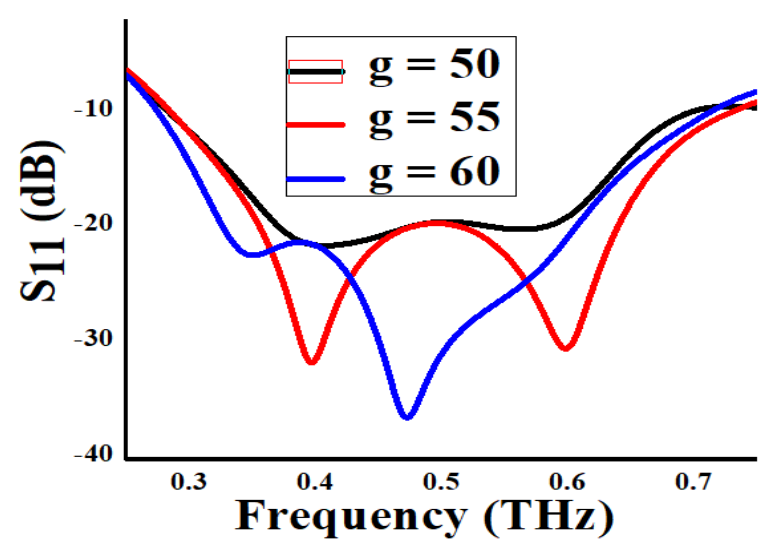

(a) By varying ' $\mathrm{g}$ ' in $\mu \mathrm{m}$

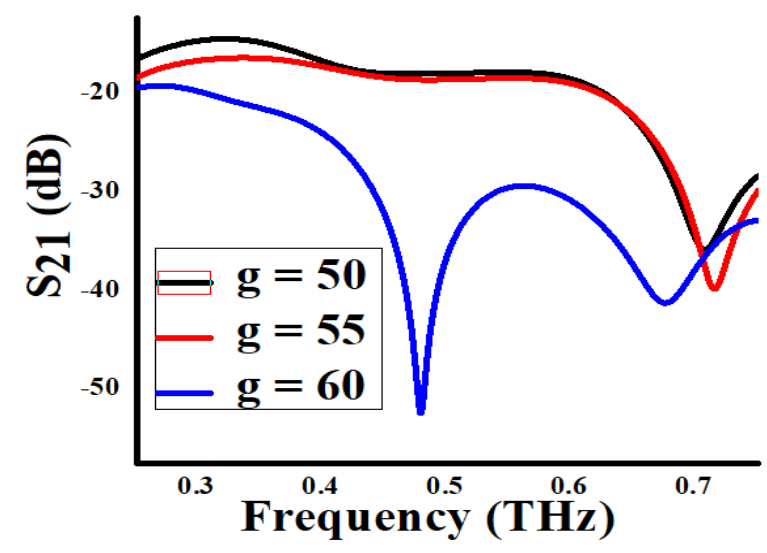

(b) By varying ' $\mathrm{g}$ ' in $\mu \mathrm{m}$ 


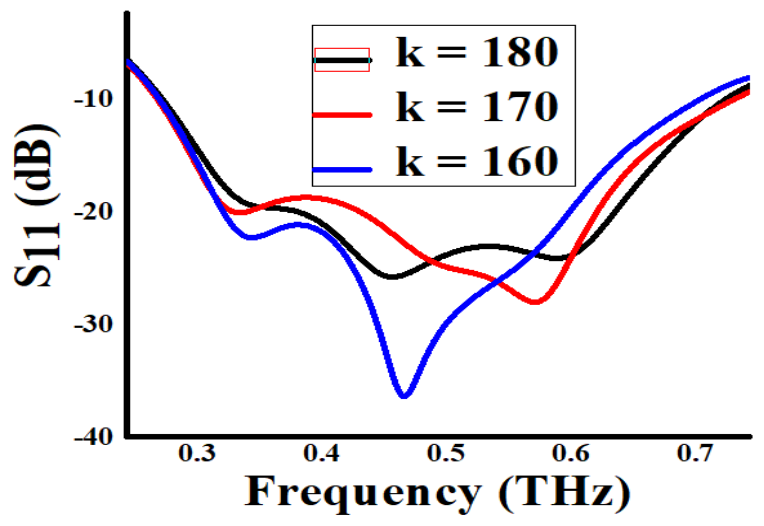

(c) By varying ' $\mathrm{k}$ ' in $\mu \mathrm{m}$

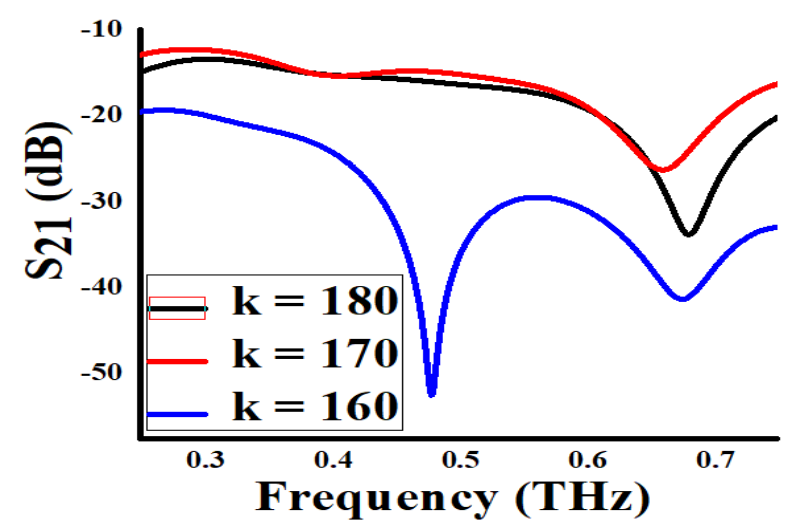

(d) By varying ' $k$ ' in $\mu \mathrm{m}$

Fig. 5Parametric Variations of parameters $g$ and $k$ in terms of $S_{11} \& S_{21}$.

\subsection{Effect of chemical potential $\left(\mu_{c}\right)$ on $S_{11}$ and $S_{21}$ characteristics}

The tuning of the chemical potential of graphene material can affect the resonance characteristics of the MIMO antenna. In fact, the resonant frequency of the antenna can be tuned based on the variations of chemical potential $\left(\mu_{\mathrm{c}}\right)$ which leads to flexible control of the resonance of the designed antenna. The tunability of resonance response by varying various chemical potentials of the graphene is shown in Fig. 6. Fig. 6 (a) shows the variation of frequency with TM02 mode of operation. It can be identified that the resonant frequency varies almost linearly with respect to the change in chemical potential $\left(\mu_{\mathrm{c}}\right)$. The variations in S-parameters $\left(S_{11}\right.$ and $\left.S_{21}\right)$ as a function of uniform change in $\mu_{\mathrm{c}}$ are depicted in Fig. 6 (b) and 6 (c), respectively. The resonant frequency shifts towards higher resonance with an increment in the value of chemical potential.

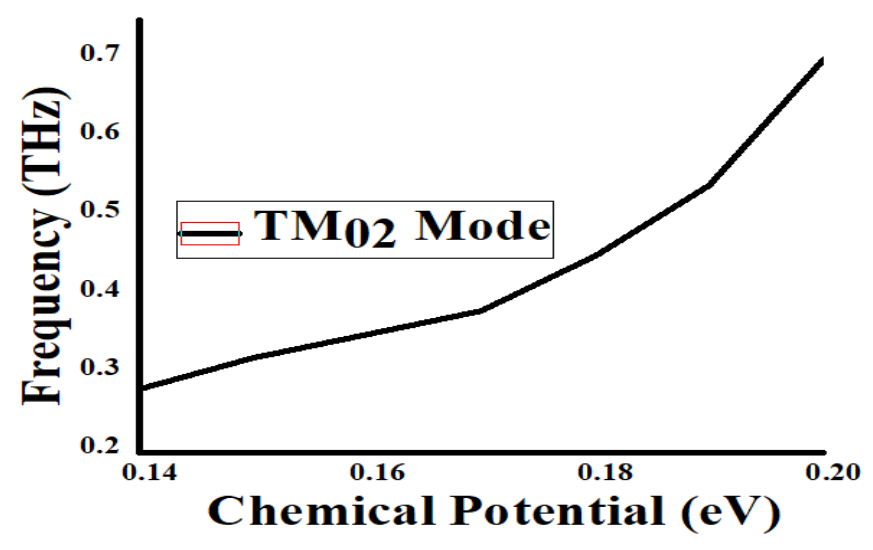

(a) Variation in frequency of $\mathrm{TM}_{02}$ mode as a function of $\mu_{\mathrm{c}}$ 

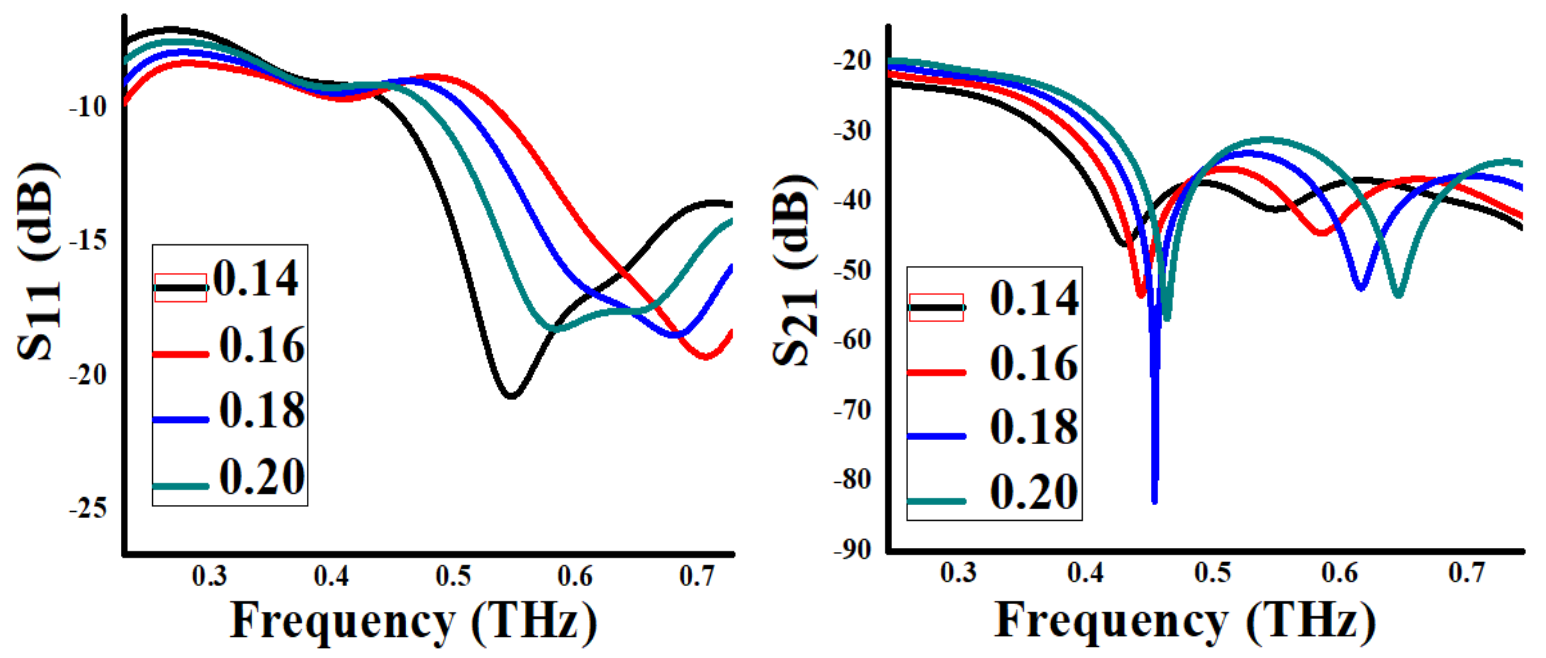

(b) $S_{11}$ parameter variations due to change in $\mu_{\mathrm{c}}(\mathrm{c}) \mathrm{S}_{21}$ parameter variations due to change in $\mu_{\mathrm{c}}$

Fig. 6 Variations of frequency in $\mathrm{TM}_{02}$ mode and $\mathrm{S}$ - parameters as a function of incremental variations in chemical potentials $\left(\mu_{\mathrm{c}}\right)$

\section{Result analysis and discussions}

\subsection{S-Parameters}

The response of the simulated S-parameters of the dual-port MIMO antenna is depicted in Fig. 7. Due to the symmetry of the antenna structure, the reflection coefficients of the designed MIMO system at the dual-ports are the same $\left(\mathrm{S}_{11}=\mathrm{S}_{22}\right)$. It is indicated that the designed MIMO structure shows an attractive wideband resonance characteristic covering 0.276 to $0.711 \mathrm{THz}$ with an impedance bandwidth of $435 \mathrm{GHz}$ for $\mathrm{S}_{11} \leq-10 \mathrm{~dB}$ which is $88.14 \%$ fractional bandwidth with respect to the center frequency at $0.4935 \mathrm{THz}$. The transmission coefficient $\left(\mathrm{S}_{21}\right)$ is maintained below $-20 \mathrm{~dB}$ over the entire operating band for the proposed MIMO design. A maximum transmission coefficient of about $-52 \mathrm{~dB}$ is obtained at $0.472 \mathrm{THz}$. It indicates very high isolation between the antenna elements which is very essential for an efficient MIMO antenna design.

\subsection{Surface Current distribution}

The distribution of surface currents of the proposed THz MIMO design at the resonant frequency of 0.472 THzis shown in Fig. 8. Fig. 8 (a) shows the distribution of surface currents when port \# 1 of the device is excited. In this condition, very high surface currents are concentrated at the edges of the feeding line and also at the edges of the patch. Similarly, when port \# 2 of the device is 
excited, the surface current distributions are highly concentrated on the second patch feeding line and the surrounding edges of the patch. However, for the proposed MIMO structure, distributions of surface currents are more prominent and stronger at the higher operating frequency for the purpose of characteristics improvement at a higher resonance.

\subsection{Radiation Characteristics}

Fig. 9 shows the representation of far-field radiation patterns in $\mathrm{E}$ and $\mathrm{H}$ planes at $0.472 \mathrm{THz}$ with excitation of port \#1 and port \#2. The $\mathrm{E}$ and $\mathrm{H}$ plane radiation patterns are represented in terms of co-pol and cross-pol components. The proposed monopole MIMO configuration exhibits almost identical radiation patterns for the excitation of port 1 and port 2 except slight variation in the cross-pol pattern of the $\mathrm{H}$ plane for the port\#2 excitation. In the E plane, the co-polarization radiation patterns resemble bi-directional and cross-polarization patterns are omnidirectional for the excitation of port \#1 and port \#2. Similarly, the H plane patterns are observed with separate excitations at dual ports. The proposed MIMO antenna maintains the desired monopole like omnidirectional co-polarization radiation patterns in the H-plane. Relatively low crosspolarization levels of below $-20 \mathrm{~dB}$ are attained for both the principal planes, which is quite acceptable. The radiation efficiency and gain of the proposed MIMO structure are also evaluated and presented in Fig. 10. The variations of the radiation efficiency are presented in Fig. 10 (a). The radiation efficiency of the proposed antenna varies from $72 \%$ to $84 \%$ over the entire operating band. The radiation efficiency of $79.16 \%$ is recorded at the resonant frequency of the proposed antenna. The gain vs frequency plot of the proposed antenna is depicted in Fig. 10 (b). The proposed MIMO structure shows positive gain characteristics over the entire wideband range of 0.276 to $0.711 \mathrm{THz}$. The peak gain of the antenna reaches $3.9 \mathrm{dBi}$ within the operating terahertz frequency band. 


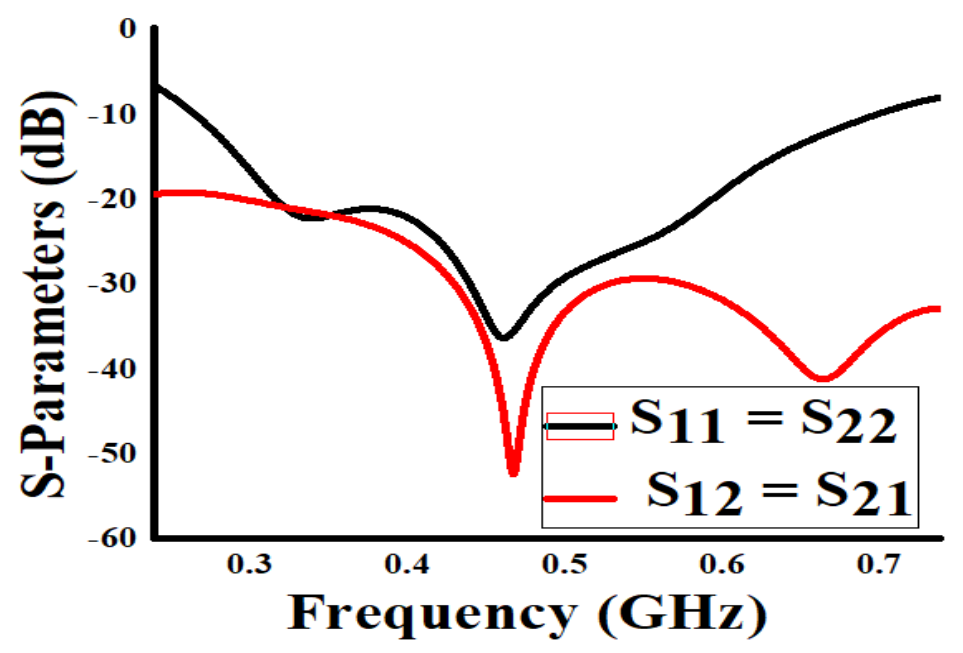

Fig. 7. S-parameters of the proposed wideband THz MIMO antenna
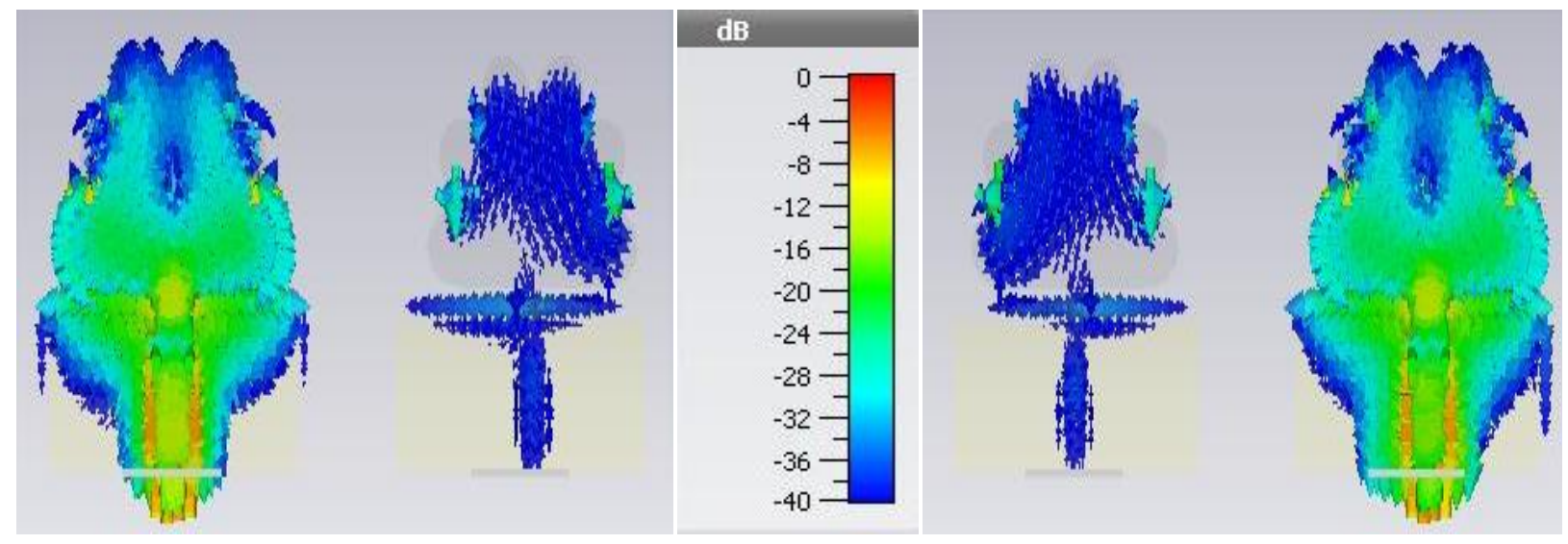

(a) Port 1 and port 2 excited front plane
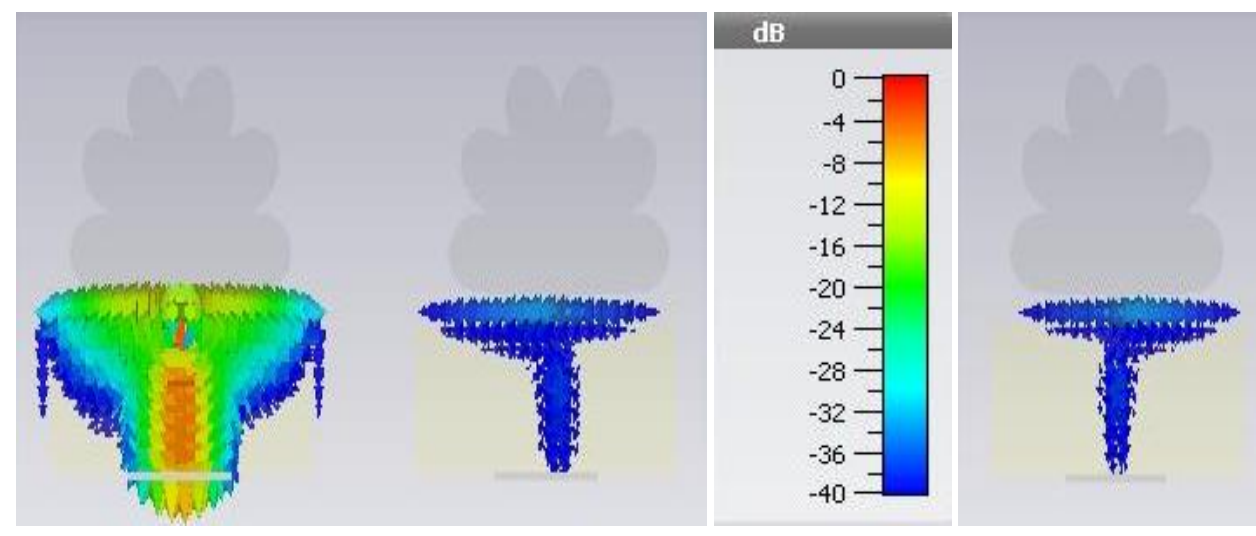

(b) Port 1 and port 2 excited ground plane

Fig. 8.Surface current distribution of THz MIMO antenna 

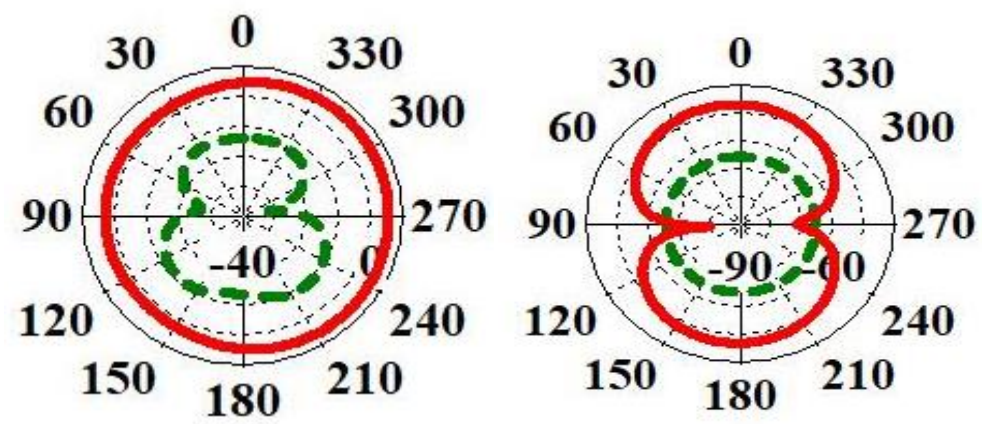

(a) Port 1 excited at $0.472 \mathrm{THZ}$
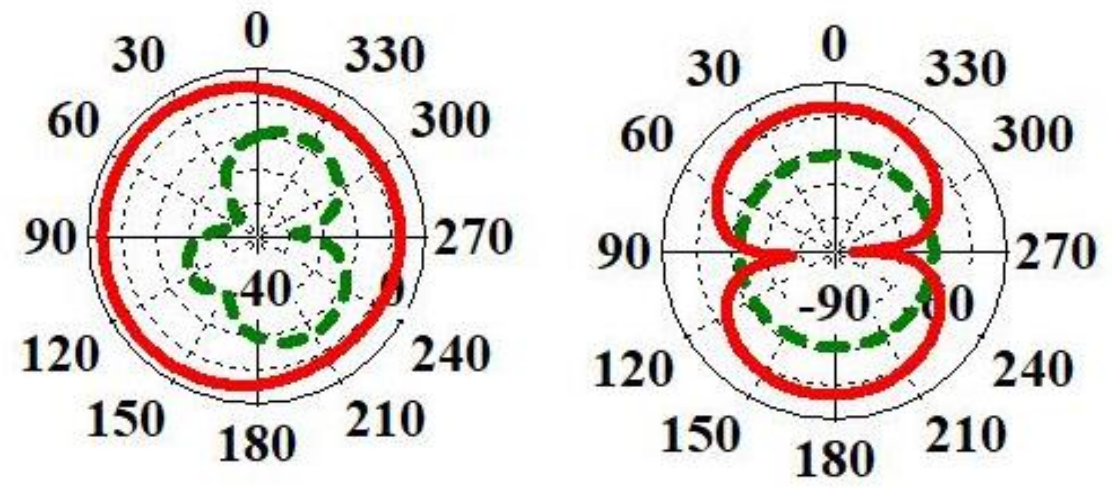

(b) Port 2 excited at $0.472 \mathrm{THZ}$

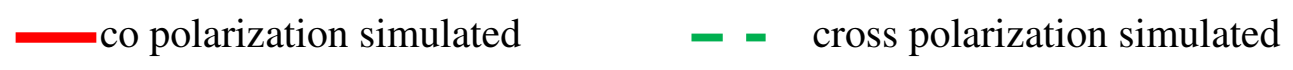

Fig. 9.Radiation patterns of THz MIMO antenna at $0.472 \mathrm{THz}$

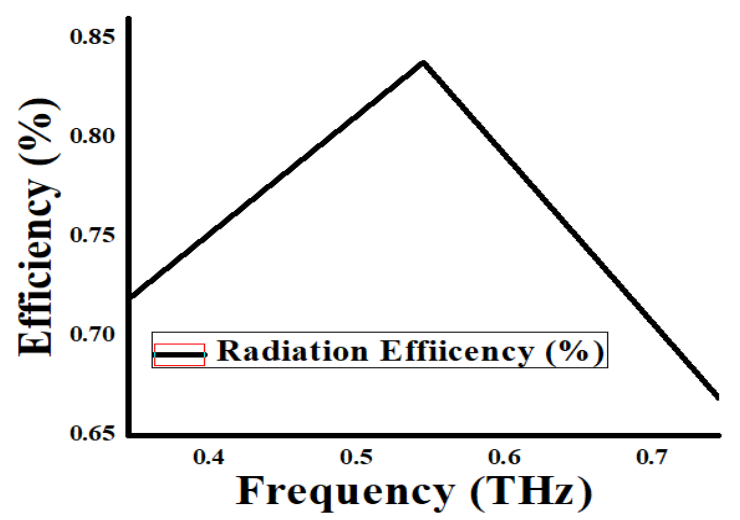

(a) Radiation Efficiency

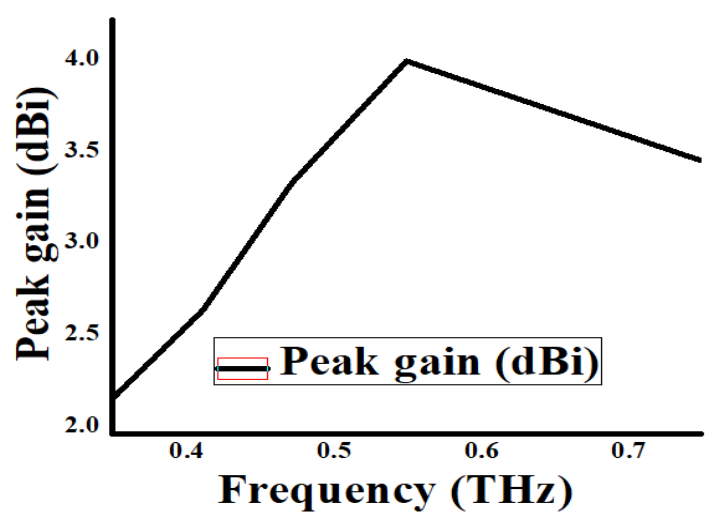

(b) Peak gain

Fig. 10. Radiation efficiency and peak gain characteristics of THz MIMO design 


\section{Analysis of MIMO parameters}

In order to ensure the compatibility of the designed wideband $\mathrm{THz}$ antenna in MIMO applications, the envelope correlation coefficient (ECC) and diversity gain (DG), total active reflection coefficient (TARC), channel capacity loss (CCL) and mean effective gain (MEG) parameters are evaluated and discussed. These MIMO performance evaluation parameters are shown in Fig.11.

\subsection{Envelope correlation coefficient (ECC)}

The parameter ECC defines the amount of correlation of far-field radiation pattern excited at different ports of the MIMO structure. ECC of any MIMO design must be as small as $<0.5$. [41]. It is evaluated by far-field parameters at the corresponding resonant frequency using equation (6) reported [42].

$$
\rho_{\mathrm{ij}}=\left|\frac{\iint\left(\mathrm{E}_{\theta_{\mathrm{i}}} \cdot \mathrm{E}_{\theta_{\mathrm{j}}}^{*}+\mathrm{E}_{\varphi_{\mathrm{i}}} \cdot \mathrm{E}_{\varphi_{\mathrm{j}}}^{*}\right) \mathrm{d} \Omega}{\iint\left(\mathrm{E}_{\theta_{\mathrm{i}}} \cdot \mathrm{E}_{\theta_{\mathrm{i}}}^{*}+\mathrm{E}_{\varphi_{\mathrm{i}}} \cdot \mathrm{E}_{\varphi_{\mathrm{i}}}^{*}\right) \mathrm{d} \Omega \iint\left(\mathrm{E}_{\theta_{\mathrm{j}}} \cdot \mathrm{E}_{\theta_{\mathrm{j}}}^{*}+\mathrm{E}_{\varphi_{\mathrm{j}}} \cdot \mathrm{E}_{\varphi_{\mathrm{j}}}^{*}\right) \mathrm{d} \Omega}\right|^{2}
$$

Here $\rho_{\mathrm{ij}}$ is the Envelope Correlation Coefficient (ECC) of antenna $\mathrm{i}^{\text {th }}$ and $\mathrm{j}^{\text {th }}$ elements of the system and $\Omega$ represents the solid angle. The evaluation of ECC using far-field radiation parameters is a complex procedure. Another way of measuring ECC using the S-parameters method by equation (7) reported in [43].

$$
\rho_{\mathrm{ij}}=\frac{\left|\mathrm{S}_{11}^{*} \mathrm{~S}_{12}+\mathrm{S}_{21}^{*} \mathrm{~S}_{22}\right|^{2}}{\left(1-\left(\left|\mathrm{S}_{11}\right|^{2}+\left|\mathrm{S}_{21}\right|^{2}\right)\right)\left(1-\left(\left|\mathrm{S}_{22}\right|^{2}+\left|\mathrm{S}_{12}\right|^{2}\right)\right)}
$$

The ECC vs. frequency result of the proposed design is shown in Fig. 11(a). It can be observed that ECC remains less than 0.001 across the entire wide operating bandwidth $(0.276-0.711 \mathrm{THz})$ of the antenna. Furthermore, the ECC is recorded as 0.0458 at the resonant frequency of 0.472 THz. The lower value of the obtained ECC indicates a lower correlation between antenna elements. The values are well below the acceptable limit of 0.5 that guarantees good MIMO performance of the proposed antenna. 


\subsection{Diversity Gain (DG)}

Diversity techniques are used to reduce the impact of fading by combining antenna elements that experience different fading. The diversity gain is defined as the time-averaged difference between signal-to-noise ratio combined within diversity antenna system and its corresponding single antenna system within single diversity of the channel. The parameter DG can be evaluated in terms of maximum theoretical diversity gain $(10 \mathrm{~dB})$ and envelope correlation coefficient by using equation (8) reported in [42]. The higher value of diversity gain means better isolation between the patch elements of the MIMO antenna. The DG should be greater than $9.95 \mathrm{~dB}$. As drawn in Fig. 11 (b), the approximate values of DG are greater than $9.99 \mathrm{~dB}$ throughout the entire operating band of the antenna. This ensures very good diversity performance of the proposed MIMO structure.

$$
\mathrm{DG}=10 \sqrt{1-|\mathrm{ECC}|^{2}}
$$

\subsection{Mean Effective Gain (MEG)}

The Mean Effective Gain (MEG) is a measure of the amount of average power received by the diversity antenna in the fading environment relative to the sum of average powers that would have been received by two isotropic antennas. It illustrates the performance gain of the MIMO antenna with consideration of their environmental effects. The MEG is evaluated at both ports of the designed structure using equation (9) as indicated in [44].

$$
\mathrm{MEG}_{\mathrm{i}}=0.5 \eta_{\mathrm{i}, \mathrm{rad}}=0.5\left[1-\sum_{\mathrm{j}=1}^{\mathrm{M}}\left|\mathrm{S}_{\mathrm{ij}}\right|^{2}\right]
$$

Here, $\mathrm{M}$ indicates the total number of ports in MIMO design and radiation efficiency $\left(\mathrm{n}_{\mathrm{i}}\right.$, rad $)$ of the current MIMO design structure. The value of MEG should be $-3 \mathrm{~dB}$ at each port of the device and the difference between both ports must be approximately $0 \mathrm{~dB}$ to ensure better diversity performance. The current MIMO structure design follows the limits in acceptable ranges. Fig. 11 (c) shows the frequency vs. MEG which is remaining around $-3 \mathrm{~dB}$ and also identified that the variation among MEG 1 and MEG 2 is almost $0 \mathrm{~dB}$. 


\subsection{Total Active Reflection Coefficient (TARC)}

When using multiple ports Total Active Reflection Coefficient (TARC) is the best parameter to represent the radiation performance and frequency response [45]. TARC (Total Active Reflection Coefficient) is defined as the ratio of the square root of the total reflected power divided by the square root of the total incident power in a MIMO system. TARC accounts for mutual coupling along with random signal combinations between ports. It is represented by equation (10) using reflected \& incident waves. It can also be evaluated by using equation (11) in terms of Sparameters as reported in [46]. The TARC of the proposed MIMO antenna is shown in Fig. 11(d). The obtained result is suitable for the intended applications for the best MIMO performance in the THz band.

$$
\Gamma_{\mathrm{a}}^{\mathrm{t}}=\frac{\sqrt{\sum_{\mathrm{j}}^{\mathrm{M}}\left|\mathrm{b}_{\mathrm{j}}\right|^{2}}}{\sqrt{\sum_{\mathrm{j}}^{\mathrm{M}}\left|\mathrm{a}_{\mathrm{j}}\right|^{2}}}
$$

Here $a_{j}$ and $b_{j}$ indicate the incident and reflected waves.

$$
\Gamma_{\mathrm{a}}^{\mathrm{t}}=\sqrt{\frac{\left|\mathrm{S}_{11}+\mathrm{S}_{12} \mathrm{e}^{\mathrm{j} \theta}\right|^{2}+\left|\mathrm{S}_{21}+\mathrm{S}_{22} \mathrm{e}^{\mathrm{j} \theta}\right|^{2}}{2}}
$$

Where ' $\theta$ ' represents the phase of the signal input.

\subsection{Channel Capacity Loss (CCL)}

Another important parameter is Channel Capacity Loss (CCL) to evaluate the MIMO performance of the designed $\mathrm{THz}$ antenna. The channel capacity loss defines the maximum limit of the information transmission rate without significant loss. It should be $<0.5 \mathrm{bits} / \mathrm{s} / \mathrm{Hzf}$ for a well designed MIMO system to indicate lossless information transmission. The CCL parameter can be obtained by using equation (12) reported in [46].

$$
\begin{aligned}
& \mathrm{C}_{\text {loss }}=-\log _{2} \operatorname{det}\left(\mathrm{a}^{\mathrm{R}}\right) \\
& a^{R}=\left(\begin{array}{l}
\rho_{11} \rho_{12} \\
\rho_{21} \rho_{22}
\end{array}\right)
\end{aligned}
$$




$$
\rho_{i i}=1-\left(\left|S_{i i}\right|^{2}+\left|S_{i j}\right|^{2}\right) \text {, and } \rho_{i j}=-\left(s_{i i}^{*} S_{i j}+s_{i j}^{*} S_{j j}\right) \text {, where } i, j=1 \text { or } 2
$$

Where $\mathrm{a}^{\mathrm{R}}$ indicates the correlation matrix at the receiving antenna.

The simulated CCL is presented in Fig. 11(e). It is recorded below the specified limit for the proposed THz MIMO antenna. Its value is only $0.00018 \mathrm{bits} / \mathrm{s} / \mathrm{Hz}$ at the resonant frequency of $0.472 \mathrm{THz}$ for the proposed MIMO design. So, with the available CCL, it can be confirmed that the proposed antenna delivers more transmission data rate in any scattering environment.

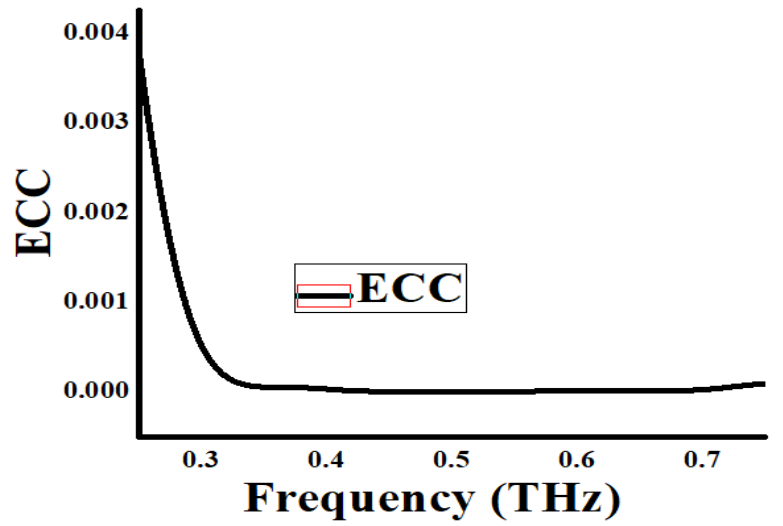

(a)

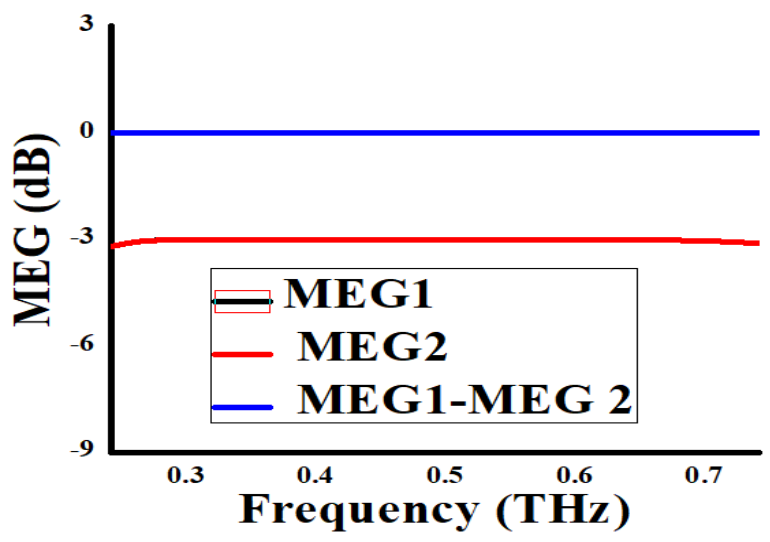

(c)

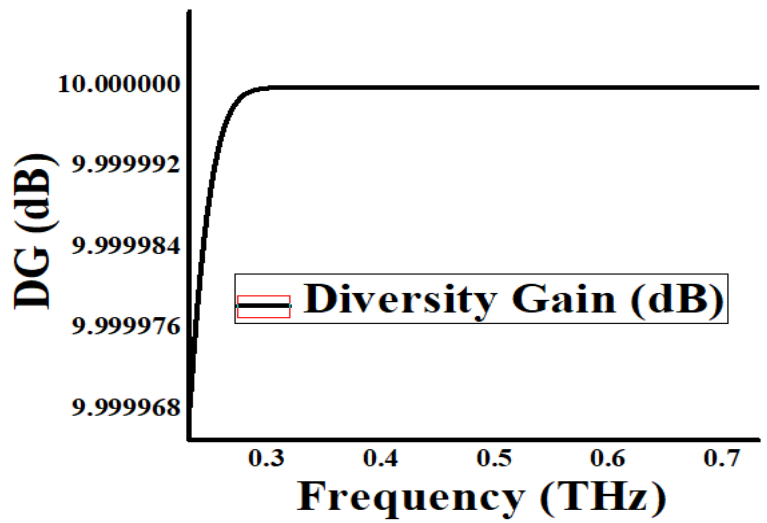

(b)

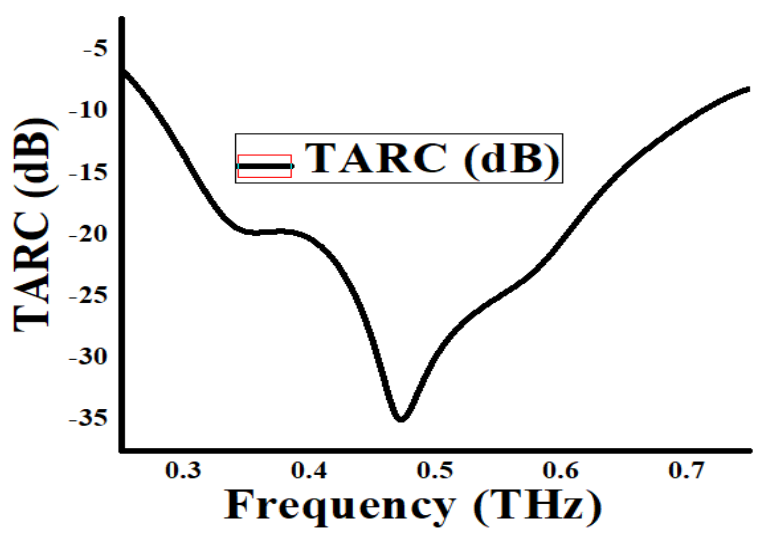

(d) 


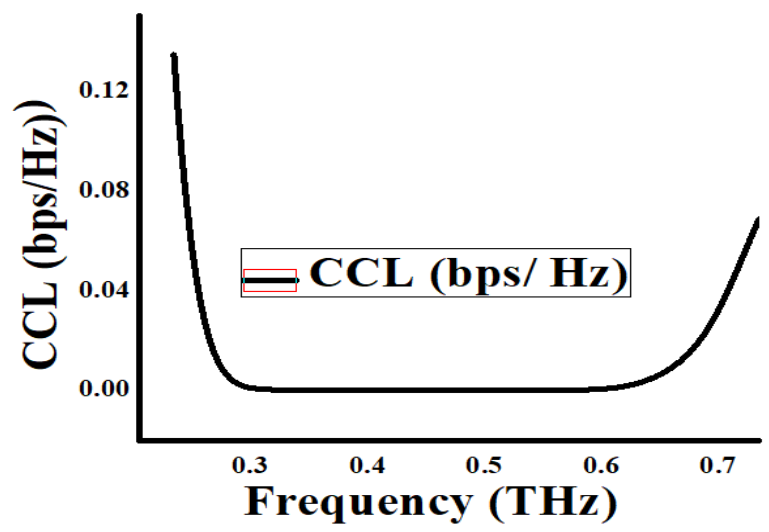

(e)

Fig. 11. MIMO parameters (a) ECC (b) Diversity Gain (c) MEG (d) Total Active Reflection Coefficient (TARC) (e) Channel Capacity Loss (CCL)

\section{Performance analysis with some other printed THz antennas}

The performance of the proposed terahertz MIMO antenna is compared with some other microstrip $\mathrm{THz}$ antennas. The analyzed performance comparison is summarized in Table 2. It is clear from the comparison table that the proposed antenna offers broader impedance bandwidth and requires the smallest dimension as compared with reported single element $\mathrm{THz}$ antenna structures [25-32], multi-layered THz array antenna structure [33], and recently reported MIMO antenna structures [34-35]. So, the novelty of the proposed design is wider impedance bandwidth in relatively smaller antenna size along with good impedance, radiation, and diversity characteristics as discussed in the preceding sections of the manuscript.

Table 2: Comparison Table with existing THz designs

\begin{tabular}{|c|c|c|c|c|c|c|}
\hline References & $\begin{array}{c}\text { Size of the } \\
\text { antenna structure } \\
\left(\boldsymbol{\mu m}^{2}\right)\end{array}$ & Substrate & $\begin{array}{c}\text { Operating } \\
\mathbf{C e n t e r} \\
\mathbf{f r e q u e n c y} \\
\mathbf{( T H z )}\end{array}$ & $\begin{array}{c}-\mathbf{1 0 d B} \\
\text { Bandwidth } \\
\mathbf{( T H z})\end{array}$ & $\begin{array}{c}\text { Bandwidt } \\
\mathbf{h} \\
\mathbf{( \% )}\end{array}$ & $\begin{array}{c}\text { Antenna } \\
\text { configuration }\end{array}$ \\
\hline$[25]$ & $800 \times 600 \times 191.29$ & Polyimide & 0.6332 & $0.615-0.6514$ & 5.75 & $\begin{array}{c}\text { Single } \\
\text { element }\end{array}$ \\
\hline$[26]$ & $600 \times 600 \times 90$ & Polyimide & 0.65 & $0.5-0.8$ & 46.15 & $\begin{array}{c}\text { Single } \\
\text { element }\end{array}$ \\
\hline$[27]$ & $500 \times 500$ & Pyrex & & $\begin{array}{c}\text { Narrowband } \\
\text { (value Not } \\
\text { reported) }\end{array}$ & $\begin{array}{c}\text { Not } \\
\text { Reported }\end{array}$ & $\begin{array}{c}\text { Single } \\
\text { element }\end{array}$ \\
\hline
\end{tabular}




\begin{tabular}{|c|c|c|c|c|c|c|}
\hline [28] & $1000 \times 1000$ & $\begin{array}{c}2 \mathrm{D} \\
\text { Electromagneti } \\
\text { c crystal } \\
\text { substrate }\end{array}$ & 0.775 & $0.6-0.95$ & 34.3 & $\begin{array}{l}\text { Single } \\
\text { element }\end{array}$ \\
\hline [29] & $1000 \times 1000$ & $\begin{array}{c}\text { RT/Duriod } \\
6006\end{array}$ & 0.775 & $0.7-0.85$ & 19.35 & $\begin{array}{l}\text { Single } \\
\text { element }\end{array}$ \\
\hline [30] & $700 \times 600$ & $\begin{array}{l}\text { RT/Duriod } \\
6006\end{array}$ & 0.775 & $0.7-0.85$ & 19.35 & $\begin{array}{l}\text { Single } \\
\text { element }\end{array}$ \\
\hline [31] & $1000 \times 1000$ & $\begin{array}{l}\text { RT/Duroid } \\
6006\end{array}$ & 0.7 & $0.6-0.8$ & 22.47 & $\begin{array}{l}\text { Single } \\
\text { element }\end{array}$ \\
\hline [32] & $1200 \times 460$ & $\begin{array}{l}\text { RT/Duroid } \\
6006\end{array}$ & 0.3065 & $0.258-0.355$ & & $\begin{array}{l}\text { Single } \\
\text { element }\end{array}$ \\
\hline [33] & $1122 \times 280$ & $\begin{array}{c}\text { indium } \\
\text { phosphide } \\
\text { (InP) and } \\
\text { benzocyclobute } \\
\text { ne (BCB). }\end{array}$ & 0.335 & $0.294-0.376$ & 27.3 & $\begin{array}{l}\text { Multilayer } \\
\text { array }\end{array}$ \\
\hline [34] & $2000 \times 1000$ & $\begin{array}{c}\text { Rogers } \\
\text { RO4835-T }\end{array}$ & 0.15 & $0.093-0.207$ & 76 & MIMO \\
\hline [35] & $1600 \times 800$ & Polyimide & 0.809 & $0.618-1.0$ & 57.96 & MIMO \\
\hline $\begin{array}{l}\text { Proposed } \\
\text { Structure }\end{array}$ & $600 \times 300$ & Polymide & 0.4935 & $0.276-0.711$ & 88.14 & MIMO \\
\hline
\end{tabular}

\section{Conclusion}

In this paper, a graphene based wideband microstrip MIMO antenna for terahertz wireless communication applications is proposed. The performance of the proposed design has been analyzed and discussed in terms of its various antenna characteristics parameters like impedance bandwidth, surface current distribution, reflection coefficient, gain, efficiency, radiation characteristics. Furthermore, different diversity parameters like ECC, DG, TARC, MEG and CCL are also investigated and presented to confirm the suitability of the proposed antenna for MIMO applications. The proposed THz MIMO antenna resonates at $0.472 \mathrm{THz}$ with a return loss of -39 $\mathrm{dB}$ and exhibits a wide impedance bandwidth characteristics covering 0.276 to $0.711 \mathrm{THz}$ frequency spectrum in the terahertz regime. The designed antenna maintains isolation $<-20 \mathrm{~dB}$ over the entire operating range with maximum isolation of $-52 \mathrm{~dB}$ at resonant frequency 0.472 THz. The good MIMO performance is ensured by attaining the MIMO performance parameters [ECC $(<0.01)$, CCL $(<0.5), \operatorname{MEG}(\leq-3 \mathrm{~dB}), \mathrm{DG}(\approx 10 \mathrm{~dB})$, and TARC $(\leq 10 \mathrm{~dB})$ ] within 
acceptable limits. The proposed MIMO antenna is suitable for high speed short distance indoor communication applications, video-rate imaging, biomedical imaging, sensing, and security scanning in the terahertz frequency band.

\section{References}

[1] C. Systems. (2019). Cisco Visual Networking Index: Global Mobile Data Traf_c Forecast Update, White Paper 2017_2022. Accessed: Jan. 5, 2020.[Online]. Available:

https://www.cisco.com/c/en/us/solutions/collateral/service-provider/visual-networking-index-vni/white-paperc11-738429.html

[2] Ying Z. Antenna in cellular phones for mobile communication. Proc IEEE. 2012; 7:2286-2296.

[3] Rappaport TS, Sun S, Mayzus R, et al. Millimeter wave Mobile communications for 5G cellular: it will work! IEEE Access. 2013; 1:335-349

[4] Singh, Rohit and Lehr, William and Sicker, Douglas and Huq, Kazi Mohammed Saidul, Beyond 5G: The Role of THz Spectrum (July 25, 2019). TPRC47: The 47th Research Conference on Communication, Information and Internet Policy 2019, Available at SSRN: https://ssrn.com/abstract $=3426810$ or http://dx.doi.org/10.2139/ssrn.3426810

[5] I. F. Akyildiz, J. M. Jornet, and C. Han, "Terahertz band: next frontier for wireless communications," Physical Communication, vol. 12, pp. 16-32, 2014.

[6] Yejun He1, Yaling Chen1, Long Zhang1,*, Sai-Wai Wong1, Zhi Ning Chen2An Overview of Terahertz Antennas, china communications, 124-165, 2020

[7] Krishna C. M, Das S, Nella A, Lakrit S, Madhav BTP, A micro-sized rhombus shaped THz antenna for high speed short range wireless communication applications, plasmonics (2021), doi/10.1007/s11468-021-01472-Z

[8] Gao, M., Li, K., Kong, F. et al. Graphene-Based Composite Right/Left-Handed Leaky-Wave Antenna at Terahertz. Plasmonics15, 1199-1204 (2020). https://doi.org/10.1007/s11468-020-01130-w

[9] G. Varshney, Reconfigurable graphene antenna for THz applications: a mode conversion approach, Nanotechnology, 31, 135208.

[10] S. M. Shamim, Muhammad Shahin Uddin, Md. Rabiul Hasan, MousumeSamad, Design and implementation of miniaturized wideband microstrip patch antenna for high-speed terahertz applications, Journal of Computational Electronics https://doi.org/10.1007/s10825-020-01587-2

[11] Shamim, S.M., Das, S., Hossain, M.A. et al. Investigations on Graphene-Based Ultra-Wideband (UWB) Microstrip Patch Antennas for Terahertz (THz) Applications. Plasmonics (2021). https://doi.org/10.1007/s11468-021-01423-8

[12] M. Zhou, Y. Cheng, "D-band high-gain circular- polarized plate array antenna," IEEE Transactions on Antennas and Propagation, vol. 66, no. 3, 2018, pp. 1280-1287. 
[13] Vrashney G, Tunable terahertz dielectric resonator antenna, Silicon 13, 1907-1915, 2021.

[14] L. Saurabh, AnujBhatnagar, and Sunil Kumar, "Design and performance analysis of bow-tie photoconductive antenna for THz application," Proc. 2017 International Conference on IntelligentComputing and Control (I2C2), 2017, pp. 1-3.

[15] Bassam Khamaisi, Samuel Jameson, EranSocher, A 210-227 GHz transmitter with integrated on-chip antenna in $90 \mathrm{~nm}$ CMOS technology, IEEE Trans. Terahertz Sci. Technol. 3.2 (2013) 141-150.

[16] A. T. Devapriya and S. Robinson, "Investigation on metamaterial antenna for Terahertz applications", J.Microw.Optoelectron. Electromagn.Appl. Vol. 18, 2019.

[17] $\mathrm{Ke} \mathrm{Wu}$, et al., Substrate-integrated millimeter-wave and terahertz antenna technology, Proc. IEEE 100.7 (2012) 2219-2232.

[18] Ka-Ming Mak, et al., A magneto electric dipole leaky-wave antenna for millimeter wave application, IEEE Trans. Antenn. Propag. 65.12 (2017) 6395-6402.

[19] Florian Formanek, et al., Aspheric silicon lenses for terahertz photoconductive antennas, Appl. Phys. Lett. 94.2 (2009) 021113.

[20] Alvaro Gonzalez, et al., Terahertz corrugated horns (1.25-1.57 THz): design, Gaussian modeling, and measurements, IEEE Trans. Terahertz Sci. Technol. 7.1 (2017) 42-52

[21] Dhillon, Amarveer Singh, Divesh Mittal, and Ekambir Sidhu. "THz rectangular microstrip patch antenna employing polyimide substrate for video rate imaging and homeland defence applications." Optik 144 (2017): 634-641.

[22] Sirmaci, Y. Denizhan, Cagdas K. Akin, and Cumali Sabah. "Fishnet based metamaterial loaded THz patch antenna." Optical and Quantum Electronics 48.2 (2016): 168.

[23] L. C. Paul, M. Islam, Proposal of wide bandwidth and very miniaturized having dimension of $\mu \mathrm{m}$ range slotted patch THz microstrip antenna using PBG substrate and DGS, in $20^{\text {th }}$ International Conference of Computer and Information Technology, ICCIT (2017), pp. 1-6

[24] S. Anand, D. Sriram Kumar, R.Wu,M. Chavali, Graphene nanoribbon based terahertz antenna on polyimide substrate. Optik125(19), 5546-5549 (2014)

[25]Kushwaha, R.K., Karuppanan, P., Malviya, L.D.: Design and analysis of novel microstrip patch antenna on photonic crystal in THz. Phys. B 545, 107-112 (2018)

[26] A. Hocini, M.N. Temmar, D. Khedrouche, M. Zamani, Novel Approach for the Design and Analysis of a Terahertz Microstrip Patch Antenna Based on Photonic Crystals, (2019), https://doi.org/10.1016/j.photonics.2019.100723

[27] A. Nejati, R. A. Sadeghzadeh, F. Geran, "Effect of photonic crystal and frequency selective surface implementation on gain enhancement in the microstrip patch antenna at terahertz frequency", Physica B 449(2014)113-120

[28] G singh, Design considerations for rectangular microstrip patch antenna on electromagnetic crystal substrate at terahertz frequency, Infrared Physics \& Technology 53 (2010) 17-22. 
[29]Aditi Sharma and G. Singh, "Rectangular Microstrip Patch Antenna Design at THz Frequency for Short Distance Wireless Communication Systems", J Infrared MilliTerahz Waves (2009) 30:1-7 DOI 10.1007/s10762-008-9416-Z

[30] R.H.Mahmud, “Terahertz microstrip patch antennas for the surveillance applications”, Kurdistan Journal of Applied Research (KJAR), Vol.5, pp. 17-27, 2020, DOI:10.24017/science.2020.1.2

[31] M. Younssi, A. Jaoujal, M. H. D. Yaccoub, A. El Moussaoui, and N. Aknin, "Study of a Microstrip Antenna with and Without Superstrate for Terahertz Frequency", International Journal of Innovation and Applied Studies, Vol. 3, pp. 369-371, 2013.

[32] Shahid Ullah, Cunjun Ruan, Muhammad Shahzad Sadiq, TanveerUlHaq\&Wenlong He (2020) Microstrip system on-chip circular polarized (CP) slotted antenna for $\mathrm{THz}$ communication application, Journal of Electromagnetic Waves and Applications, 34:8, 1029-1038,DOI: 10.1080/09205071.2020.1770130

[33] Hamsakutty Vettikalladi,Waleed Tariq Sethi, Ahmad Fauzi Bin Abas,Wonsuk Ko, Majeed A. Alkanhal,and Mohamed Himdi, Sub-THz Antenna for High-Speed Wireless Communication Systems, International Journal of Antennas and Propagation, Volume 2019, Article ID 9573647, 9 pages

https://doi.org/10.1155/2019/9573647

[34]TayfunOkan, High efficiency unslotted ultra-wideband microstrip antenna for sub-terahertz short range wireless communication systems, Optik, Volume 242, 2021, 166859

[35] M. Singh, S. Singh, M.T. Islam, Highly efficient ultra wideband MIMO patch antenna array for short range THz applications, Emerging Trends in Terahertz Engineering and System Technologies Devices, Materials, Imaging, Data Acquisition and Processing, https://doi.org/10.1007/978-981-15-9766-4, pp. 193-207, 2021.

[36] Rodrigues, Nilton RNM, Rodrigo de Oliveira, and Victor Dmitriev. "Smart terahertz graphene antenna: operation as an omnidirectional dipole and as a reconfigurable directive antenna." IEEE Antennas and Propagation Magazine 60.5 (2018): 26-40.

[37] Hanson, George W. "Erratum:“Dyadic Green's functions and guided surface waves for a surface conductivity model of graphene"[J. Appl. Phys. 103, 064302 (2008)]." Journal of Applied Physics 113.2 (2013): 029902.

[38] Bala, Rajni, and AnupmaMarwaha. "Characterization of graphene for performance enhancement of patch antenna in THz region." Optik 127.4 (2016): 2089-2093.

[39] Kazemi, Amir Hossein, FatemehFouladiMahani, and ArashMokhtari. "Peak amplitude enhancement of photoconductive antenna using periodic nanoslit and graphene in the THz band." Optik 185 (2019): 114-120.

[40] Abadal, Sergi, et al. "Time-domain analysis of graphene-based miniaturized antennas for ultra-short-range impulse radio communications." IEEE Transactions on communications 63.4 (2015): 1470-1482.

[41]Babu, K. Vasu, and B. Anuradha. "Design of inverted L-shape \& ohm symbol inserted MIMO antenna to reduce the mutual coupling." AEU-International Journal of Electronics and Communications 105 (2019): 42-53. 
[42] Sree, Gorre Naga Jyothi, and Suman Nelaturi. "Design and experimental verification of fractal based MIMO antenna for lower sub 6-GHz 5G applications." AEU-International Journal of Electronics and Communications 137 (2021): 153797.

[43] K. Vasu Babu, B. Anuradha, S. Das. "Design \& analysis of a dual band MIMO antenna to reduce the mutual coupling”, 2019 JINST14P09023

[44] Nasir, Jamal, et al. "A reduced size dual port MIMO DRA with high isolation for 4G applications." International Journal of RF and Microwave Computer-Aided Engineering 25.6 (2015): 495-501. 28

[45] Manteghi, Majid, and YahyaRahmat-Samii. "Broadband characterization of the total active reflection coefficient of multiport antennas." IEEE Antennas and Propagation Society International Symposium. Digest. Held in conjunction with: USNC/CNC/URSI North American Radio Sci. Meeting (Cat. No. 03CH37450). Vol. 3. IEEE, 2003. 29

[46] Sharawi, Mohammad S. "Printed multi-band MIMO antenna systems and their performance metrics [wireless corner]." IEEE Antennas and Propagation Magazine 55.5 (2013): 218-232. 30 